\title{
PEM Yakıt Hücresi Akış Alanlarının Üç Boyutlu Modellenmesi
}

\author{
Hüseyin Kahraman ${ }^{1 *}$, İsmail Özgün ${ }^{2}$ \\ 1* Sakarya Uygulamalı Bilimler Üniversitesi, Teknoloji Fakültesi, Makine Mühendisliği Bölümü, Sakarya, Türkiye, (ORCID: 0000-0003-3322-9904), \\ huseyink@subu.edu.tr \\ 2 Sakarya Uygulamalı Bilimler Üniversitesi, Teknoloji Fakültesi, Makine Mühendisliği Bölümü, Sakarya, Türkiye (ORCID: 0000-0002-7829-6337), \\ y180009014@subu.edu.tr
}

(International Symposium on Multidisciplinary Studies and Innovative Technologies (ISMSIT) 2021 - 21-23 October 2021)

(DOI: $10.31590 /$ ejosat.1017474)

ATIF/REFERENCE: Kahraman, H. \& Özgün, İ. (2021). PEM Yakıt Hücresi Akış Alanlarının Üç Boyutlu Modellenmesi. Avrupa Bilim ve Teknoloji Dergisi, (29), 65-69.

$\ddot{O} \mathbf{z}$

Polimer elektrolit membran (PEM) yakıt hücreleri, çevre dostu olmaları, yüksek enerji verimlilikleri gibi avantajları sebebiyle gelecekte içten yanmalı motorlara alternatif olarak gösterilmektedir. PEM yakıt hücrelerinde bipolar plakalar üzerinde yer alan gaz akış kanalları, reaktant gazların hücre aktif alanı üzerinde dolaştırılmasını ve elektrokimyasal reaksiyonlar sonucunda oluşan suyu hücreden atılmasını sağlamaktadır. Akış kanal tasarımı yakıt hücresi performansı açısından önemli bir yere sahiptir ve bu konuda literatürde birçok çalışma yer almaktadır. Bu çalışmada reaktant gaz dağılımının daha homojen olduğu ve su tahliye kabiliyetinin daha iyi olduğu bir akış kanal tasarımı geliştirilmeye çalışılmıştır. Bu kapsamda doğadan esinlenerek bir yaprak tasarım ve murray kanununa göre oluşturulan yaprak tasarım modelleri literatürde sıkça karşılaşmakta olduğumuz serpantin tasarım modeli ile karşılaştırılmış̧ır. Yapılan çalışma Ansys FLUENT programı kullanılarak Hesaplamalı Akışkanlar Dinamiği (HAD) yöntemi ile gerçekleştirilmiştir. Çalışmada $4 \mathrm{~cm} 2$ aktif alana sahip olan yakıt hücresi modelleri için analizler gerçekleştirilerek sonuçlar incelenmiştir. Hücre içerisindeki aktif alan üzerindeki akım yoğunluğu ve reaksiyon sonucu oluşan suyun membran ve katot kanallarındaki dağılımları incelenmiştir. Oluşturulan bu üç tasarımın düşük akım yoğunluklarında yaklaşık olarak aynı performanslara sahip oldukları görülmüştür. Murray kanununa göre oluşturulan yaprak tasarımın $0,8 \mathrm{~mA} / \mathrm{cm} 2$ gibi yüksek akım yoğunluklarında daha iyi performans gösterdiği görülmüştür. Buradan murray kanununa göre oluşturulan bu yaprak tasarımın su tahliye kabiliyetinin daha iyi olduğu sonucuna varılmıştır. Aynı zamanda akış kanal uzunluğunun büyük olmasının hücre performansını kötü yönde etkilediği görülmüştür. Bu çalışmada akış kanal optimizasyonunun PEM yakıt hücrelerinin yüksek akım yoğunluğu değerlerinde su yönetiminin iyileştirilerek konsantrasyon kayıplarının azaltılmasıyla performanslarının artacağını göstermiş̧ir.

Anahtar Kelimeler: PEM, Yakıt Hücreleri, Akış Kanal Modellemesi.

\section{Three-Dimensional Modeling of PEM Fuel Cell Flow Fields}

\begin{abstract}
Polymer electrolyte membrane (PEM) fuel cells have begun to attract attention due to their advantages, such as high energy efficiency and less environmental pollution. Gas flow channels located on bipolar plates in PEM fuel cells allow the distribution of reactant gas and the removal of water formed as a result of electrochemical reactions from the cell. Flow channel design has an important place in terms of fuel cell performance, and many studies on this topic are included in the literature. In this study, an attempt was made to develop a flow channel design in which the reactant gas distribution is more homogeneous and the water discharge capability is better. In this regard, a leaf design inspired by nature and leaf design models created according to murray's law have been compared with the serpentine design model, which we often encounter in the literature. The study was carried out by Computational Fluid Dynamics (HAD) method using Ansys FLUENT program. In the study, the results were examined for fuel cell models with an active area of 4 $\mathrm{cm} 2$. Current density and the distribution of water formed as a result of the reaction in the membrane and cathode channels were studied. These three designs were found to have approximately the same performance at low current densities. The leaf design created by Murray's law was found to perform better at high current densities such as $0.8 \mathrm{~mA} / \mathrm{cm} 2$. From here, it is concluded that this leaf design, created according to murray's law, has a better ability to drain water. At the same time, large flow channel length was found to have a bad effect on cell performance. In this study, flow channel optimization showed that PEM fuel cells would improve their performance by improving water management at high current density values and reducing concentration losses.
\end{abstract}

Keywords: PEM, Fuel Cells, Flow Field Modeling.

*Hüseyin Kahraman: huseyink@subu.edu.tr 


\section{Giriş}

Günümüzde kullanılmakta olan petrol kökenli yakıtların yenilenebilir enerji kaynağı olmamasının yanında çevreye vermiş olduğu zarar düşünüldüğünde alternatif enerji kaynakları arayışını kaçınılmaz hale getirmektedir. Yakıt hücreleri, enerji ve çevre sorunlarına alternatif bir çözüm olarak görülmektedir. Yüksek dönüşüm verimliliği, kompakt yapıda olmaları ve emisyon problemlerinin olmaması gibi avantajları yakıt hücrelerini, içten yanmalı motorlara ve portatif uygulamalarda akülerin ve pillerin yerini alabilecek bir teknoloji haline getirmiştir. Yakıt hücresi çeşitleri arasında, proton değişim membranı (PEM) yakıt hücresi düşük çalışma sıcaklıkları ve yüksek verimleriyle daha fazla dikkat çekmektedir (Lim vd., 2020).

Bir yakıt hücresinin ana problemlerinden biri, katot reaksiyonu tarafından üretilen sudur, çünkü oksijenin gaz difüzyon katmanından katalizör yüzeyine geçişini engeller. Bununla birlikte, su oksijen akışı ile uzaklaştırılır. Ayrıca, bir PEM yakıt hücresi, elektrik güç çıkışına benzer bir miktar atık 1s1 üretir, böylece enerji verimliliğini yaklaşık \%50 ile sınırlar (Wen vd., 2018). Bu 1s1 esas olarak üç nedenden dolayı üretilir: elektrokimyasal reaksiyonlar, ohmik 1sıtma ve su yoğunlaşması. Yakıt hücrelerinde akış alanı tasarımı yakıt hücresinin performansını önemli ölçüde etkilemektedir. Mevcut araştırma sonuçları göstermektedir ki, uygun akış alanı tasarımının yakıt hücresi performansını önemli ölçüde artırabilir aynı zamanda da reaktant gaz dağılımının da homojen olmasını buna bağlı olarak da hücre içerisinde oluşabilecek direncin de az olmasını sağlayacaktır. Bu çalışmada da daha önceki yapılmış çalışmalar doğrultusunda yakıt hücresi performansını iyileştirebilmek ve uygun akış alanı tasarımını elde etmek amacıyla sayısal modelleme yöntemiyle serpantin ve doğadan esinlenerek modellenen yaprak tasarımının karşılaştırması yapılmıştır (Anyanwu vd., 2019).

PEM yakıt hücresi akış kanalları hakkında literatürde birçok çalışma bulunmaktadır. Kanal genişlik ve derinliği (Wang vd., 2010), (Chang \& Wu, 2015), (Cooper vd., 2016), daralankanal kesitleri ve kanallar içine eklenen engeller (Ghasabehi vd., 2021), (Shen vd., 2019), (Heidary vd., 2017), metal köpükler (Liu vd., 2020), (Zhang vd., 2021), (Bao vd., 2020), (Azarafza vd., 2019) gibi çok farklı yaklaşımlar literatürde araştırmacılar tarafından çalışılmıştır. Bu çalışmada yakıt hücrelerinde geleneksel olan serpantin tasarım ile yenilikçi bir yaklaşım ile bitki yapraklarında bulunan damarların yakıt hücresi akış kanallarına uyarlanması ile elde ettiğimiz tasarımlar kıyaslanmıştır.

\section{Materyal ve Metot}

\subsection{Modelde Yapılan Kabuller}

Bu çalışmada kullanılan yakıt hücresi modelinde aşağıdaki kabuller göz önünde bulundurularak analizler yapılmıştır:

- Reaksiyona giren türler ideal gaz özelliğine sahiptir.

- Sistem kararlı yapıdadir.

- Reaktant gaz akışının laminer ve sıkıştırılamaz olduğu kabul edilmiştir.

- Membranın, katalizör ve gaz difüzyon tabakasının izotropik ve homojen olarak kabul edilir.

- Yakıt hücresi bileşenlerinde ohmik (dirençsel) potansiyel düşüş ihmal edilmiştir.

Yakıt hücrelerinde bipolar plakalar üzerinde yer alan ve reaktant gazların dağılımını, reaksiyon sonucu oluşan ürünlerin hücreden atılmasını sağlayan akış kanal tasarımları yakıt hücresi performansını etkileyen en önemli etkenlerden biridir. $\mathrm{Bu}$ çalışmada da bu konuyla ilgili olarak serpantin tasarım, doğadan esinlenerek oluşturulan yaprak tasarım ve murray kanununa göre oluşturulan yaprak tasarım modeli farklı çalışma koşullarında Ansys FLUENT 19.0 ( karşılaştırılmıştır. Hesaplamalı Akışkanlar Dinamiği (HAD) kullanımı; kütle, enerji ve 1sı taşınımı, elektrokimyasal reaksiyonlar ve potansiyel alanlar gibi yakıt hücresi içerisinde gerçekleşen birçok olayın bir yakıt hücresinin üretilmeden maliyetleri ortadan kaldırarak geliştirilmesini sağlar. Yapılan çalışmada yakıt hücresi modelleri belirlenen çalışma şartlarında çözümleri gerçekleştirilmiştir.

Bipolar plakalar üzerinde bulunan akış kanalı tasarımları ve yakıt hücresinin bileşenleri SOLIDWORKS CAD programı kullanılarak oluşturulmuştur. Oluşturulan bu geometriler literatürde sıkça karşılaşmış olduğumuz serpantin tasarım, doğadan esinlenerek oluşturulan yaprak tasarım ve murray kanununa göre oluşturulan yaprak tasarım modelinden oluşmaktadır. Şekil 1'de modellenen yakıt hücrelerine ait geometrik boyutları daha sade görebilmek amacıyla tek kanallı bir yakıt hücresi modeli üzerinde yakıt hücresinin bileşenleri gösterilmiştir. Modelde kullanılan yakıt hücresi boyutları Tablo 1 'de verilmiştir.

Tablo 1. Modelde kullanılan yakıt hücrelerinin boyutları.

\begin{tabular}{lcc}
\hline \hline & & \\
\hline Akı̀n toplayıcı plaka kalınlığı & 2 & $\mathrm{~mm}$ \\
Gaz difüzyon tabakası kalınlığı & 0,3 & $\mathrm{~mm}$ \\
Katalizör tabakası kalınlığı & 0,01 & $\mathrm{~mm}$ \\
Membran kalınlığı & 0,05 & $\mathrm{~mm}$ \\
Akış kanalı genişliği & 1 & $\mathrm{~mm}$ \\
Akış kanalı derinliği & 1 & $\mathrm{~mm}$ \\
Yakıt hücresi toplam kalınlığı & 4,67 & $\mathrm{~mm}$ \\
Aktif alan (serpantin tasarım) & 4 & $\mathrm{~cm}^{2}$ \\
Aktif alan (yaprak tasarım) & 3,992 & $\mathrm{~cm}^{2}$ \\
\hline
\end{tabular}




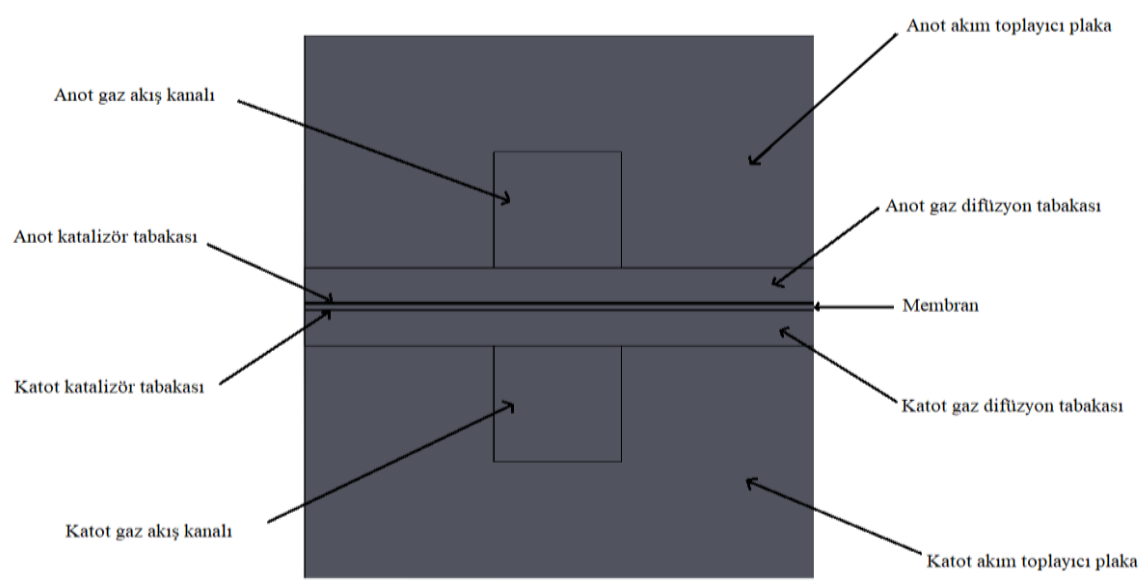

Şekil 5.1: Tek kanallı bir yakıt hücresinin şematik gösterimi.

\section{Araştırma Sonuçları ve Tartışma}

Polarizasyon eğrileri, ideal hücre voltajına ulaşılmasına engel olan yakıt hücresi kayıplarının görülebilmesini sağlayarak hücre performansı kıyaslamada önemli bir yere sahiptir. Bir polarizasyon eğrisinde genel olarak Şekil 2.9'da gösterildiği gibi aktivasyon kayıpları, ohmik kayıplar ve konsantrasyon kayıları olarak üç bölgede kayıplar yaşanmaktadır. Yaşanan bu kayıplarla ilgili detaylı bilgi Bölüm 2.4'de verilmişti. Sonuçlar incelendiğinde incelenen yakıt hücresi tasarımları için üç farklı kayıp bölgesi açık olarak görülebilmektedir. Bunun yanında farklı akış kanalı tasarımları için düşük akım yoğunluklarında akış kanalı tasarımının önemli bir etkisi görülmemiştir ki bu sonuç literatürde incelenen çalışmalarla da tutarlıdır. Bunun sebebi ise reaksiyon hızlarının düşük akım yoğunluklarında düşük olması ve buna bağlı olarak da akış kanallarındaki düşük su içeriğidir. Yüksek akım yoğunluklarında, akış kanal geometrisi, reaktant gazların dağılımını engelleyen su içeriğinin verimli bir şekilde azaltılmasında ve böylece konsantrasyon kayılarının azaltılmasında önemli bir rol üstlenir.

Yapılan çalışmada elde edilen sonuçlara göre yakıt hücresi polarizasyon eğrilerinde gerilim ile akım yoğunluğu arasındaki değişim Şekil 6.2'de görüldüğü gibi gerçekleşmiştir. Grafik değerleri belirlenen hücre voltajlarında $(0,45 \mathrm{~V}, 0,55 \mathrm{~V}, 0,65 \mathrm{~V}$, $0,75 \mathrm{~V}, 0,85 \mathrm{~V})$ ve çalışma koşullarında elde edilen sonuçları göstermektedir. Murray kanununa göre oluşturulan yaprak tasarım modelinin su tahliye kabiliyetinin yüksek oluşuna bağlı olarak konsantrasyon kaybının yaşandığı bölgede iyi sonuçlar vererek hücre performansında artış sağlandığı söylenebilir.

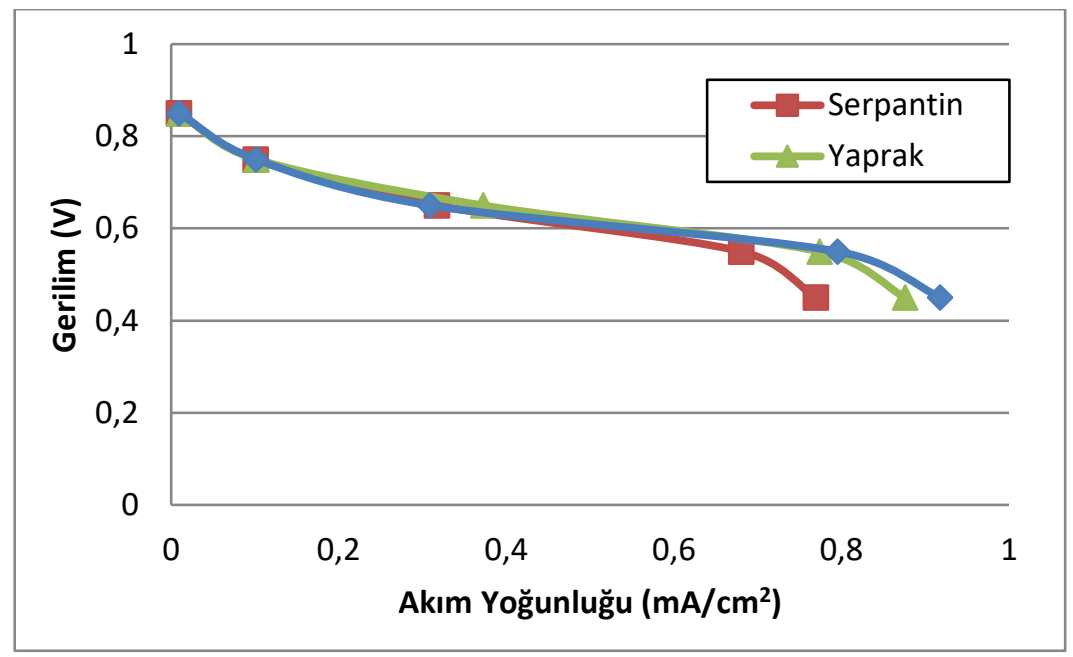

Şekil 2. Serpantin, yaprak ve murray kanuna göre oluşturulan yaprak tasarımlarının farklı hücre voltajlarında elde edilen performans verileri.

Yakıt hücresi polarizasyon eğilerinde verilen gerilim-akım yoğunluğu arasındaki değişim, yakıt hücresinin genel olarak performansını göstermektedir. Buna rağmen katot katalizör/gaz difüzyon tabakası ara yüzeyindeki akım yoğunluğu dağılımı da incelenmiştir. Şekil 3'te incelenen yakıt hücresi tasarımlarına ait $0,75 \mathrm{~V}$ hücre voltajında elde edilen akım yoğunluğu dağılımları görülmektedir. Akım yoğunluğu dağılımı bir yakıt hücresinde akış kanallarının ne ölçüde sağlıklı çlıştığının önemli bir göstergesidir.
Deneysel olarak bu ölçümler oldukça maliyetli deney setleri ile ölçülebilirken, simülasyon yardımıyla maliyet ve zamandan tasarruf ederek gerçeğe yakın sonuçlar bilgisayar ortamında elde eilebilmektedir. Akım yoğunluğu dağılımının yakıt hücresi aktif alanının her yerinde homojen olması istenir. Bunu sağlanabilmesi için reaktant gazların tüm yüzey üzerinde homojen bir şekilde dağıtılması gerekmektedir. Ayrıca bilhassa katot reaksiyonu sonucu oluşan sıvı suyun da akış kanalları vasıtasıyla hücre dışına 
başarılı şekilde tahliye edilmesi gerekmektedir. Aksi halde yakıt hücresi katalizör tabakası üzerinde farklı bölgelerde farklı akım yoğunlukları elde edilir. Reaksiyon hızının yüzey ortalamasından fazla olduğu bölgelerde yüksek akım üretilecek ve bölgeler arasında termal gerilimler oluşacaktır. Sıcak noktaların membran ve katalizör ömrünü azalttığı bilinen bir gerçektir. Ayrıca yüksek akım üretilen bölgelerde doğal olarak yüksek miktarda sıv1 su üretilecek ve homojen olmayan bu sıvı su ürünü bir bölgede yoğunlaşarak gaz difüzyon tabakasının gözeneklerini bu bölgede dolduracaktır. $\mathrm{Bu}$ bölgelerdeki katalizör tanecikleri su ile kaplanacak ve reaksiyon hızı oldukça düşecektir. Burada yakıt hücresi aktif alanı üzerinde kimyasal reaksiyonların hangi bölgelerde daha yoğun gerçekleştiği ve hangi bölgelerden daha fazla akım yoğunluğu elde edildiği görülebilmektedir. Analiz sonuçlarına dikkat edilecek olursa akım yoğunluğu dağılımı geliştirilen yaprak tasarım modellerinde daha eşit dağılıma sahipken serpantin tasarımda bu durumun aksine çıkışa doğru reaksiyonların yavaşlamasına bağlı olarak akım yoğunluğu azalmıştır.

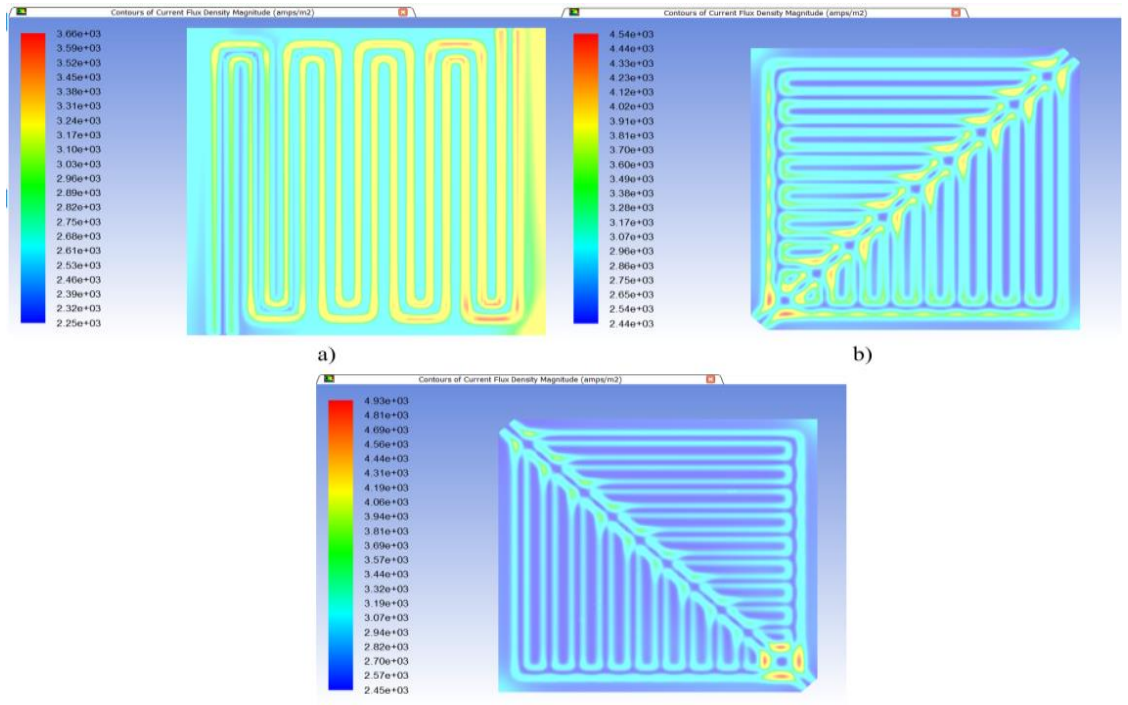

c)

Şekil 3. 0,75 V hücre voltajında katot katalizör/gaz difüzyon tabakası ara yüzeyindeki akım yoğunluğu dă̆llımları; a) serpantin tasarım, b) yaprak tasarım, c) murray kanununa göre oluşturulan yaprak tasarım.

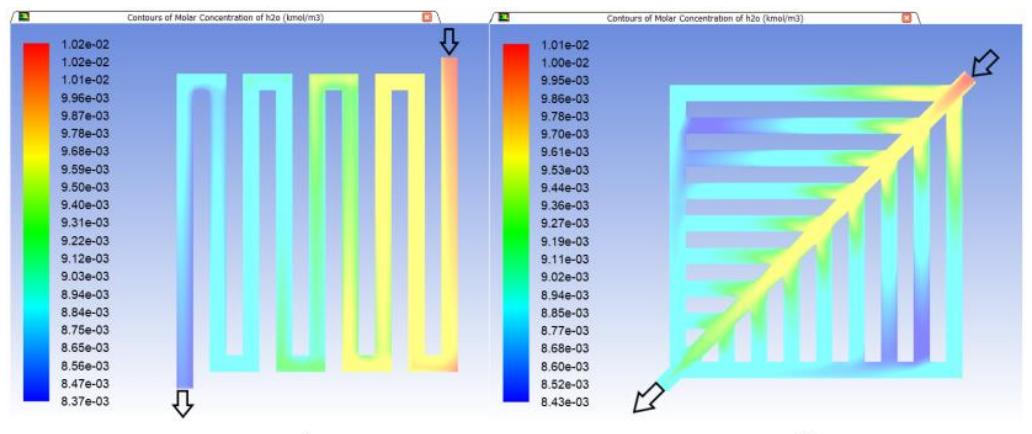

a)

b)

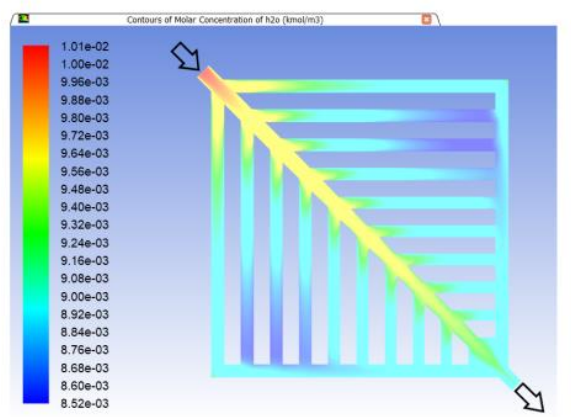

c)

Şekil 6.12: 0,75 V hücre voltajında katot kanallarındaki suyun molar konsantrasyon dă̆llımlarl; a) serpantin tasarım, b) yaprak tasarım, c) murray kanununa göre oluşturulan yaprak tasarım. 


\section{Sonuç}

$\mathrm{Bu}$ çalışmada; serpantin, yaprak ve murray kanununa göre oluşturulan yaprak tasarıma sahip PEM yakıt hücresi modelleri sayısal olarak incelenmiştir. Sonuç olarak yüksek akım yoğunluğu değerlerinde doğadan esinlenerek oluşturulan modellerin hücre performansını artırdığı gözlemlenmiştir. Buradan geliştirilen modellerin su yönetimi konusunda geleneksel serpantin tasarımdan daha iyi olduğu sonucuna varılmıştır. Bunun yanında reaktant dağılımları ve akım yoğunluğu dağılımlarının da hücrede eşit dağılımıda sağlanmıştır.

Yapılan çalışmada, murray kanununa göre oluşturulan tasarımın serpantin tasarıma kıyasla daha iyi olduğu görüldüğü halde yan kanallarda da dallanma yapısının oluşturulması ve yan kanalların bitişinde yer alan kanalın geliştirilmesinin su tahliye kabiliyetini daha da iyileştirecektir. Daha büyük aktif alana sahip yakıt hücrelerinde yan kanallardaki dallanma yapısındaki artış kanal uzunluğunu azaltacağından ve daha homojen dağılım sağlayacağından hücre performansını artıracaktır. Aynı zamanda yan kanalların bitişinde yer alan ve tüm bu yan kanallardaki oluşan suyun hücreden dişarı atılmasını sağlayan kanalın geliştirilmesi su tahliye kabiliyetini daha da artıracak buna bağlı olarak da yüksek akım yoğunluklarında yaşanan konsantrasyon kayıpları azalacaktır.

\section{Kaynakça}

Anyanwu, I. S., Hou, Y., Xi, F., Wang, X., Yin, Y., Du, Q., \& Jiao, K. (2019). Comparative analysis of two-phase flow in sinusoidal channel of different geometric configurations with application to PEMFC. International Journal of Hydrogen Energy, 44(26), 13807-13819. https://doi.org/10.1016/j.ijhydene.2019.03.213

Azarafza, A., Ismail, M. S., Rezakazemi, M., \& Pourkashanian, M. (2019). Comparative study of conventional and unconventional designs of cathode flow fields in PEM fuel cell. Renewable and Sustainable Energy Reviews, 116, 109420. https://doi.org/10.1016/j.rser.2019.109420

Bao, Z., Niu, Z., \& Jiao, K. (2020). Gas distribution and droplet removal of metal foam flow field for proton exchange membrane fuel cells. Applied Energy, 280, 116011. https://doi.org/10.1016/j.apenergy.2020.116011

Chang, D.-H., \& Wu, S.-Y. (2015). The effects of channel depth on the performance of miniature proton exchange membrane fuel cells with serpentine-type flow fields. International
Journal of Hydrogen Energy, 40(35), 11659-11667. https://doi.org/10.1016/j.ijhydene.2015.04.153

Cooper, N. J., Smith, T., Santamaria, A. D., \& Park, J. W. (2016). Experimental optimization of parallel and interdigitated PEMFC flow-field channel geometry. International Journal of Hydrogen Energy, 41(2), 1213-1223. https://doi.org/10.1016/j.ijhydene.2015.11.153

Ghasabehi, M., Ashrafi, M., \& Shams, M. (2021). Performance analysis of an innovative parallel flow field design of proton exchange membrane fuel cells using multiphysics simulation. Fuel, 285, 119194. https://doi.org/10.1016/j.fuel.2020.119194

Heidary, H., Kermani, M. J., Prasad, A. K., Advani, S. G., \& Dabir, B. (2017). Numerical modelling of in-line and staggered blockages in parallel flowfield channels of PEM fuel cells. International Journal of Hydrogen Energy, 42(4), 2265-2277. https://doi.org/10.1016/j.ijhydene.2016.10.076

Lim, K., Vaz, N., Lee, J., \& Ju, H. (2020). Advantages and disadvantages of various cathode flow field designs for a polymer electrolyte membrane fuel cell. International Journal of Heat and Mass Transfer, 163, 120497. https://doi.org/10.1016/j.ijheatmasstransfer.2020.120497

Liu, R., Zhou, W., Li, S., Li, F., \& Ling, W. (2020). Performance improvement of proton exchange membrane fuel cells with compressed nickel foam as flow field structure. International Journal of Hydrogen Energy, 45(35), 17833-17843. https://doi.org/10.1016/j.ijhydene.2020.04.238

Shen, J., Tu, Z., \& Chan, S. H. (2019). Enhancement of mass transfer in a proton exchange membrane fuel cell with blockage in the flow channel. Applied Thermal Engineering, 149, $1408-1418$ https://doi.org/10.1016/j.applthermaleng.2018.12.138

Wang, X.-D., Yan, W.-M., Duan, Y.-Y., Weng, F.-B., Jung, G.-B., \& Lee, C.-Y. (2010). Numerical study on channel size effect for proton exchange membrane fuel cell with serpentine flow field. Energy Conversion and Management, 51(5), 959-968. https://doi.org/10.1016/j.enconman.2009.11.037

Wen, D., Yin, L., Piao, Z., Lu, C., Li, G., \& Leng, Q. (2018). Performance investigation of proton exchange membrane fuel cell with intersectant flow field. International Journal of Heat and Mass Transfer, 121, 775-787. https://doi.org/10.1016/j.ijheatmasstransfer.2018.01.053

Zhang, G., Bao, Z., Xie, B., Wang, Y., \& Jiao, K. (2021). Threedimensional multi-phase simulation of PEM fuel cell considering the full morphology of metal foam flow field. International Journal of Hydrogen Energy, 46(3), 2978-2989. https://doi.org/10.1016/j.ijhydene.2020.05.263 